\title{
CONCEPÇÕES DE LÍNGUA E IMPLICAÇÕES PARA A REVISÃO DE TEXTOS
}

\section{Roberto Santos de Carvalho}

Resumo: O estudo apresenta brevemente as concepções de língua, objetivismo abstrato e subjetivismo idealista que fundamentam as principais correntes linguísticas surgidas a partir do século XX, visando identificar traços delas no capítulo "Conceitos gerais", do manual Revisão de textos: teoria e prática. Para tanto, elege para a análise três aspectos abordados no manual, a saber: 1 . o conceito de revisor; 2. o ato de leitura na revisão; 3. a intervenção do revisor. A partir disso, é empreendida uma discussão sobre como a filiação explícita ou implícita a uma concepção de língua pode nortear o trabalho com a revisão de textos.

Palavras-chave: Objetivismo abstrato. Subjetivismo idealista. Revisão de textos.

\section{INTRODUÇÃo}

$\boldsymbol{T}$ odo trabalho com a revisão de textos demanda o acionamento de um amplo saber interdisciplinar para além dos pressupostos tradicionais; sendo assim, qualquer trabalho com a lingua(gem), para ser coerente do ponto de vista político-ideológico-pedagógico-metodológico, deve deixar claro o que entende por língua, pois a forma como a concebemos altera o trabalho que realizamos com ela (BAGNO, 2012; TRAVAGLIA, 2005). Desse modo, este artigo pretende resgatar e discutir, de forma breve, duas concepções de lingua que fundamentam as principais correntes linguísticas surgidas a partir do século XX e que, diretamente, impactaram a produção científica no campo da língua(gem), forjando inicialmente a nossa forma de encarar os fenômenos linguísticos.

Revisitaremos a tradição filosófica ocidental, visando resgatar a gênese do pensamento platônico que norteou as concepções de língua(gem) objeto da aná- 
lise e forneceu as bases para a construção de um edificio teórico posterior fundamentado numa filosofia dualista de língua. Após, a partir de Volochínov $(2014)^{1}$, abordaremos as concepções objetivismo abstrato e subjetivismo idealista associadas diretamente às correntes estruturalista e gerativista. Procuraremos apresentar alguns pressupostos que fundamentam essas noções, visando identificar traços de uma ou outra no capítulo "Conceitos gerais" do manual Revisão de textos: teoria e prática (ATHAYDE, 2011), elegendo para a análise três aspectos abordados no manual, a saber: 1. o conceito de revisor; 2. o ato de leitura na revisão; 3. a intervenção do revisor. A partir disso, empreenderemos uma discussão sobre como a filiação explícita ou implícita a uma concepção específica de língua pode nortear o trabalho com a revisão de textos.

\section{O Pensamento linguístico-Filosófico Platônico}

As intervenções durante o processo de revisão, ainda que inconscientemente, defluem das concepções que o revisor constrói ao longo da trajetória formativa e profissional sobre o que seja uma lingua e como se trabalha com ela. Das intervenções a serem feitas no texto de outrem, perceber e solucionar erros talvez seja a maior das preocupações de alguns revisores de texto, o que é reforçado por alguns manuais da área.

Como uma mancha negativa, o erro deve ser notado e corrigido pelo revisor, espécie de "guardião" da língua, cuja função "é ler o texto à procura de incorreções, atuando como um fiscal da língua e da linguagem. Ele deve corrigir erros sintáticos, ortográficos e de pontuação, além de adequar melhor os recursos linguísticos" (ATHAYDE, 2011, p. 14).

A noção de erro linguístico, no entanto, está assentada na filosofia dualista platônica, que se caracteriza por apresentar um par de conceitos que se opõe de forma inconciliável. Para Platão, em A República, no Mito da caverna, o mundo estava organizado em um mundo sensível, material, palpável, que podia ser percebido por meio dos sentidos, e em um mundo cognoscivel, mental, espiritual, que podia ser percebido apenas pela inteligência. Inspirado nessa forma de conceber o mundo, o pensamento ocidental pôde organizar uma série de outros pares opostos (concreto/abstrato; corpo/alma; universal/particular; objetivo/ subjetivo). Os estudos linguísticos, por conseguinte, também foram influenciados pela filosofia dualista, elegendo suas dicotomias língua versus linguagem; fala versus escrita; certo versus errado, entre outras.

A filosofia dualista, assentada num par de dicotomias, influenciou as grandes correntes linguísticas a partir dos séculos XIX/XX, notadamente o estruturalismo (sincronia versus diacronia; langue versus parole etc.) e o gerativismo (competência versus desempenho; estrutura profunda versus estrutura superficial etc.), oferecendo o pano de fundo para a construção das concepções de língua que nortearam essas correntes do pensamento linguístico ocidental.

A seguir, trataremos das concepções de língua objetivismo abstrato e subjetivismo idealista que fundamentaram o estruturalismo saussuriano e o gerativismo chomskiano, respectivamente; depois, buscaremos analisar se uma ou outra 
concepção subjaz aos pressupostos da revisão de textos apresentados no capítulo "Conceitos gerais" do manual Revisão de textos: teoria e prática (ATHAYDE, 2011) e quais implicações isso pode acarretar para a prática da revisão de textos.

\section{ObJetivismo abstrato}

Essa concepção é o axioma que fundamenta o estruturalismo linguístico saussuriano (SAUSSURE, 1995). A língua é concebida como um sistema de formas passiveis de descrição, que funciona independentemente de qualquer interferência fora do sistema, ou seja, nenhuma interferência cultural, social, ideológica afeta as formas autônomas abstratas, que funcionam em si mesmas e por si mesmas, independentemente das vontades, dos propósitos comunicacionais, das subjetividades dos sujeitos falantes e das mudanças histórico-político-sociais - a língua é um sistema de signos autônomos que se relacionam entre si, apenas, no interior de uma sociedade esquemática, abstrata.

Ao tomar a língua por esse viés, Saussure (1995) promove três exclusões para sustentar seu edifício teórico, a saber: o sujeito, o ideológico e o contexto; com essas três exclusões, a unicidade e homogeneidade passam a conferir a coerência necessária à noção de língua desenvolvida ${ }^{2}$.

É possivel sintetizar, segundo Volochínov (2014, p. 85), a concepção de língua em comento por meio dos seguintes postulados:

1 A língua é um sistema estável, imutável, de formas lingüísticas submetidas a uma norma fornecida tal e qual à consciência individual e peremptória para esta.

2 As leis da língua são essencialmente leis lingüisticas específicas, que estabelecem ligações entre os signos lingüísticos no interior de um sistema fechado. Essas leis são objetivas em relação a toda consciência subjetiva.

3 As ligações lingüísticas específicas nada têm a ver com valores ideológicos (artísticos, cognitivos ou outros). Não se encontra, na base dos fatos linguísticos, nenhum motor ideológico. Entre a palavra e seu sentido não existe vínculo natural e compreensível para a consciência, nem vínculo artístico.

4 Os atos individuais de fala constituem, do ponto de vista da lingua, simples refrações ou variações fortuitas ou mesmo deformações das formas normativas. Mas são justamente esses atos individuais de fala que explicam a mudança histórica das formas da língua; enquanto tal, a mudança é, do ponto de vista do sistema, irracional e mesmo desprovida de sentido. Entre o sistema da língua e sua história não existe nem vínculo nem afinidade de motivos. Eles são estranhos entre si.

Dessa visão abstrata emerge um nó conceitual, às vezes de difícil desembaraço, que alimenta o imaginário do senso comum (e de alguns revisores de texto sem formação na área de linguagem) sobre o que seja uma língua, uma vez que, segundo Faraco (2008, p. 32), "não existe uma definição de língua por critérios puramente linguísticos", mas fundamentalmente por critérios políticos e culturais, pois "uma língua é uma entidade cultural e política".

Desse modo, a conceituação de língua está diretamente associada ao pensamento linguístico da primeira metade do século $\mathrm{XX}$ que tinha como propósito firmar a Linguística como uma ciência autônoma no universo geral das ciências sociais, empreendimento que ocorreria à medida que ela estabelecesse seu objeto de estudo e seus métodos próprios de análise (LUCCHESI, 2004). 


\section{SubJetivismo IDEALISTA}

Essa concepção concebe a língua como uma atividade mental cuja fonte reside no psiquismo individual. Chomsky (2008, p. 18) defende que a linguagem "é uma faculdade, uma parte da mente/cérebro que é dedicada ao conhecimento e ao uso da linguagem". Como uma função particular do corpo, o órgão da linguagem assemelha-se ao sistema visual (comum a muitas espécies biológicas), diferindo dele, contudo, pelo fato de a linguagem ser uma propriedade pertencente apenas à espécie humana.

Sendo essa faculdade comum aos homens, todos nasceriam com o mesmo conjunto de dados programados biologicamente, potencializando-nos a adquirir uma língua particular. A esse estágio inicial da faculdade da linguagem, Chomsky (1994) chama Gramática Universal (GU). A GU, então,

[...] deve ser vista como uma caracterização da faculdade da linguagem geneticamente determinada. Pode se encarar essa faculdade como um mecanismo de aquisição de linguagem, uma componente inata da mente humana que origina uma língua particular, pela interação com a experiência vivida, ou ainda como um mecanismo que converte a experiência num sistema de conhecimento atingido: conhecimento de uma ou de outra língua (CHOMSKY, 1994, p. 23).

A faculdade da linguagem é comparada a uma grande rede que se conecta a um painel com interruptores por meio de uma imensa rede de fios. Os fios da rede são constituídos pelos princípios da linguagem, os interruptores caracterizam-se como opções a serem determinadas pela experiência. No momento em que os interruptores são acionados de um modo, gera-se francês, quando acionados de outro modo, gera-se japonês, português etc. Um determinado jeito de acionarmos os interruptores é o que caracteriza, nessa perspectiva teórica, cada lingua humana.

É possivel sintetizar, segundo Volochínov (2014, p. 74-75), a concepção de lingua em comento por meio dos seguintes postulados:

1 A língua é uma atividade, um processo criativo ininterrupto de construção ("energia"), que se materializa sob a forma de atos individuais de fala.

2 As leis da criação lingüística são essencialmente as leis da psicologia individual.

3 A criação lingüística é uma criação significativa, análoga à criação artística.

4 A língua, enquanto produto acabado ("ergon"), enquanto sistema estável (léxico, gramática, fonética) se apresenta como um depósito inerte, tal como a lava esfria da criação lingüística, abstratamente construída pelos lingüistas com vistas à sua aquisição prática como instrumento pronto para ser usado.

Essa forma de abordar a lingua, por ser também formalista, elege exclusivamente a sintaxe de frases isoladas como capaz de dar conta de toda a complexidade das línguas.

Chomsky, assim como Saussure, é herdeiro da filosofia de épocas anteriores que tencionavam abordar a linguagem a partir dos focos "universalista" e "particularista" (WEEDWOOD, 2002). Ambos procuravam abordar a lingua pelo viés abstrato, universalista, formal e sistêmico; ambos desconsideravam o sujeito como partícipe de uma cultura, influenciado por uma sociedade, dotado de vontade 
politica e afetado por ideologias ${ }^{3}$, fatores que interferem no uso que se faz da língua e que também contribuem para o processo de variação delas.

Em função de as concepções anteriormente abordadas considerarem a língua como uma entidade abstrata, formal e homogênea, não se debruçarem sobre o texto como unidade de análise e por excluírem o sujeito dos processos de interação verbal, faz-se necessário que o revisor transite em uma concepção de língua que procure concebê-la como um lugar primordial de luta social, de negociação de sentidos, como um lugar em que "o dizer é uma forma de fazer, de agir, de atuar" (ANTUNES, 2005, p. 30). Um lugar em que a escrita não seja um terreno uniforme, desvinculada de um propósito, e que a língua não exista em si mesma, mas como discurso. A depender de como o revisor conceba a noção de língua, a forma como se trabalha com ela estará ancorada nesse pressuposto.

\section{ConcepÇões de línguA EM UM MANUAL DE REVISÃo DE TEXTOS}

Atuando profissionalmente com a revisão de textos, encontramos alguns manuais em que explícita ou implicitamente noções de gramática, norma, correção, leitura e texto difundem uma visão do que seja uma língua, posicionando o revisor como um superleitor, cuja função de fiscal da linguagem lhe confere uma licença-interventiva muito ampla que, consideramos, deve ser discutida.

Trabalhos procuram trazer para o campo científico/acadêmico a discussão sobre a revisão e o revisor, contribuindo para desfazer mitos e equívocos que envolvem os paradigmas e o olhar diante da intervenção no texto de outrem e o processo de trabalho com a linguagem (OLIVEIRA, 2007; ROCHA, 2012).

Analisaremos o capítulo "Conceitos gerais" do manual Revisão de textos: teoria e prática (ATHAYDE, 2011), doravante Manual (2011), elegendo para a análise três aspectos abordados nele, a saber: 1. o conceito de revisor; 2. o ato de leitura na revisão; 3. a intervenção do revisor. Procuraremos situar em qual concepção de língua esses pressupostos parecem estar fundamentados e quais implicações podem acarretar para o trabalho com a revisão de textos.

O Manual (2011, p. 14) conceitua o revisor de textos como

[...] o profissional encarregado de revisar material escrito com o intuito de conferir-lhe correção, clareza concisão e harmonia, agregando valor estético e linguístico ao texto, bem como o tornando inteligível ao destinatário - o leitor - tanto quanto o autor pretenda.

A função básica do revisor profissional de textos é ler o texto à procura de incorreções, atuando como um fiscal da língua e da linguagem. Ele deve corrigir erros sintáticos, ortográficos e de pontuação, além de adequar melhor os recursos linguísticos.

Ao atribuir ao revisor a função de "agregar valor estético e linguístico", a definição parece imprecisa: o que se entende por valor estético e linguístico? Há um valor estético e linguístico que sirva como parâmetro de análise/aplicação e em que lugar é possivel encontrar tal parâmetro estético/linguístico? O valor estético/linguístico é o mesmo para os diferentes gêneros textuais? Haveria di-

Saussure e Chomsky "serão duramente criticados já no último quartel do século pelos linguistas e filósofos da linguagem que se dedicarão à abordagem funcionalista da língua e aos aspectos pragmáticos do uso da língua, bem como pelos defensores da língua como uma atividade social, sujeita portanto à pressão da ideologia" (WEEDWOOD, 2002, p. 125, grifo nosso). 
ferentes valores estéticos/linguísticos para cada prática social escrita, na proporção dos inúmeros gêneros textuais que circulam na sociedade moderna e que são objeto do trabalho de revisão? A existência de um valor estético e linguístico não estaria vinculada a um "gosto" ideológico e particular de quem o atribui ao texto de outra pessoa? Essas questões não são abordadas, reforçando a imprecisão das noções para quem deseja encontrar fundamentação para exercer o trabalho revisional no Manual (2011).

Da definição supracitada, parecem implicitas noções estáticas, leis linguísticas específicas e fixas de algo imanente para todas as enunciações, sendo o revisor aquele capaz de devolver objetivamente aos escritos certos valores caso não estejam presentes no texto a ser revisado.

Ao atribuir ao revisor a tarefa de tornar o texto inteligivel ao leitor (destinatário) "tanto quanto o autor pretenda", o revisor parece se tonar alguém que possui um superpoder a ponto de ter clara e objetivamente em mente aquilo que o autor exatamente pretendeu como propósito comunicativo, como se a língua exprimisse por si mesma um sistema fixo de normas, relações e significações em relação à consciência individual que podem ser captadas com exatidão pelo revisor diretamente da mente de outrem por meio do texto, um processo "superpsíquico".

A função de fiscal parece se encaixar perfeitamente nas noções subjacentes, pois o ato de fiscalizar pressupõe a aplicação de regras e leis previamente estabelecidas, compiladas, cabendo ao agente fiscal a aplicação vinculada e sem qualquer licença discricionária daquilo que está determinado. Ao que parece, esse raciocínio é perfeitamente aplicável e se encaixa na concepção de língua objetiva e abstrata que subjaz às afirmações do Manual (2011).

Exercendo sua ação fiscalizatória sobre o texto/a língua, o ato de leitura realizado na revisão é abordado no Manual (2011) nestes termos:

O revisor não empreende uma leitura como qualquer outra pessoa; ele praticamente radiografa as palavras, as frases, buscando seus meandros mais intimos e novas possibilidades e articulações que elas ofereçam (p. 18).

Considerando o termo revisão, a princípio, no sentido que ele tem para nós, implica "nova leitura, mais minuciosa, de um texto; novo exame" (Houaiss 2009); obviamente, a atividade está ligada à leitura, mas ela é "nova" no sentido em que o autor já leu seu texto (e o releu muitas vezes), portanto, é mais uma; nova no sentido em que ela representa novidade para o revisor, que nunca havia lido aquele trabalho e nova por ser mais outra leitura sobre o mesmo enfoque linguístico textual a ser feita pelo revisor profissional; mas, além de nova, ela é mais minuciosa, esta leitura está atenta a um sem-número de fatores aos quais o autor não dá atenção (e, a muitos deles, nem deve mesmo dar, pois prejudicaria a fluência da produção); estamos falando de novo exame, em que cada letra, cada sílaba, cada som - bem como todos os conjuntos possiveis desses elementos, será reconsiderado clinicamente, no sentido da visão metódica, racional que será aplicada sobre todos os ângulos e em oposição (ou em conjunto) com a visão empírica que o autor e seus colaboradores e orientadores terão tido do texto (p. 19-20, grifo nosso).

Outra vez, parece haver filiação implícita à noção de unidades linguísticas funcionando autonomamente em si mesmas e por si mesmas no interior do texto 
e uma visão ingênua de que seja possivel a alguém analisar letras, sílabas e som, radiografar e dissecar os seus conjuntos e possibilidades de combinação, e que isso constitua o objetivo da leitura no processo de revisão.

Volochínov (2014, p. 98) esclarece que,

[...] na prática viva da língua, a consciência linguística do locutor e do receptor nada tem a ver com um sistema abstrato de formas normativas, mas apenas com a linguagem no sentido de conjunto dos contextos possíveis de uso de cada forma particular.

Os contextos possiveis de uso não estão postos a priori e organizados na mente de um superleitor-revisor que pode acessá-los prontos e acabados ou extraí-los de algum lugar. O uso prático da língua é inseparável do seu conteúdo ideológico da vida social, que vai trazendo à existência práticas sociais e usos linguísticos a partir das necessidades comunicativas.

Colocado em condição privilegiada de leitura, capaz de fazer inferências, análises e julgamentos sob todos os ângulos que a lingua possa oferecer, conseguindo, inclusive, perceber a visão que o autor e seus colaboradores tiveram sobre o texto, surge a figura de um revisor-leitor onipresente, onisciente e onipotente detentor do domínio do sentido que, estando apto a analisar os elementos formais do texto, consegue extrair desse novo reexame o (e não um) sentido no texto (nas sílabas, nas palavras a partir de todas as combinações possiveis), parecendo não existir mais nada (de possibilidades de sentido) além disso.

Sobre o processo de leitura e construção dos sentidos, Flores e Teixeira (2013, p. 8-9, grifo nosso) esclarecem que

[...] a leitura é também fenômeno enunciativo. Reconhecer isso implica levar em conta a assimetria típica da cena enunciativa: a pessoa que interpreta um enunciado reconstrói seu sentido a partir de indicações nele presentes, mas nada garante que o que ela reconstrói coincida com as representações do enunciador. A relação intersubjetiva que se produz na leitura é sempre inédita. O sentido, longe de ser imanente, se apresenta como o resultado de um processo de apropriação do texto pelo leitor, que imprime a sua singularidade na experiência de leitura. Admitir a singularidade do ato de leitura afasta a ideia de uma interpretação definitiva e, consequentemente, leva a abandonar uma vontade de domínio sobre o sentido, a suportar um certo "luto" da interpretação.

A noção de texto abordada pelo Manual (2011) parece ser encarada como um produto e não como um processo, e a leitura do revisor parece desconsiderar que os sujeitos imprimem suas subjetividades e experiências e o fazem marcando-se na língua e isso não está dado a priori como algo imanente ao sistema. $\mathrm{O}$ revisor-leitor que emerge do Manual (2011) parece ser aquele que vai conseguir entregar o produto ao leitor tornando-o "inteligivel ao destinatário - o leitor tanto quanto o autor pretenda" como algo homogêneo e acabado. E isso se filia a uma concepção de revisão tradicional vista como uma etapa subsequente à escrita e não como uma atividade recursiva em que a revisão pode ocorrer em qualquer etapa do processo, excluindo a noção de etapas lineares (OLIVEIRA, 2016). Tais pressupostos parecem apresentar alguns traços da concepção herdada do objetivismo abstrato.

Em relação à intervenção feita pelo revisor no texto, o Manual (2011) destaca: 
Revisor de textos é o profissional encarregado de revisar material escrito com o intuito de conferir-lhe correção [...] (p. 14, grifo nosso).

Portanto, pode-se afirmar que o revisor de textos deve dominar as regras gramaticais da língua padrão do texto, bem como atentar para a redação, a revisão de provas, revisão de padrão (ou padronização textual) e revisão gramatical (p. 17, grifo nosso).

O Manual (2011) não discute o fato de que a noção de correção pode ser relativizada e não deixa claro o que seja lingua padrão do texto ${ }^{4}$, o que parece sugerir algo homogêneo.

Um revisor que cultive o pressuposto de que a língua seja um sistema de regras invariáveis estará preso à visão da correção como algo homogêneo, imutável, esvaziado de valores ideológicos e históricos. A norma/regra, então, passa a ser encarada como uma entidade com vontade própria, que não aceita, que condena um ou outro uso, cujo dizer dogmático se encerra nas gramáticas e manuais tradicionais. Estará atrelado à velha dualidade certo versus errado e seu trabalho se pautará, apenas, em intervir em nome da "norma", ainda que as peculiaridades dos gêneros, as investigações linguísticas e os propósitos comunicativos licenciem e expliquem certos usos condenados pela tradição.

O Manual (2011, p. 17) afirma:

Para fazer revisão de boa qualidade, além de consultar ferramentas (dicionários, gramáticas) que sustentam as correções realizadas, o revisor precisa conhecer a diversidade dos gêneros textuais, bem como saber respeitar as características estilisticas inerentes a cada autor.

O revisor não fará apenas correção gramatical mecânica, mas uma completa intervenção no texto a ser aperfeiçoado. O revisor pode transformar desde meras palavras aqui e ali, até parágrafos inteiros, editando-os ou enriquecendo-os com a inserção de novos vocábulos.

Ao recomendar a consulta a dicionários e a gramáticas e chamar a atenção para as peculiaridades dos gêneros textuais e o respeito ao estilo, o Manual (2011) parece se distanciar de uma concepção objetiva e abstrata de língua e abrir-se a uma perspectiva mais dialógica, mas deixa uma lacuna ao não abordar quais gramáticas e dicionários consultar, deixando transparecer que esses instrumentos de consulta possuem um dizer homogêneo ao abordarem um mesmo aspecto da lingua.

Vejamos, a esse respeito, um dos pontos de muita preocupação para alguns revisores, a regência verbal, e como ela é abordada em um dicionário. Analisemos, em especial, o caso do verbo namorar.

Suponhamos que o revisor se depare com a construção [Maria namora com um estudante de engenharia.] em um material a ser revisado. Alguém pautado na concepção de língua homogênea acionará seu saber gramatical aprendido na escola ou procurará pautar a correção a partir do saber encerrado em um instrumento normativo específico, que registra e sustenta a forma "correta" da re-

\footnotetext{
4 Existe no senso comum uma grande confusão em relação ao conceito de norma. A clareza do que sejam os conceitos de norma padrão, norma culta e norma gramatical é fundamental para o revisor de textos não cair nas armadilhas que a imprecisão dos termos e as noções do senso comum ligadas a eles podem acarretar para o trabalho de revisar textos. Para uma discussão aprofundada dos conceitos de norma, consultar Faraco (2008).
} 
gência de determinado verbo, independentemente das alterações sociais e históricas que tenham ocorrido, convertendo o suposto "erro" de regência para a única forma correta [Maria namora um estudante de engenharia.], uma vez que a tradição classifica o verbo namorar como transitivo direto, condenando como erro o complemento preposicionado (NICOLA; TERRA, 2006).

Alguns argumentarão que [namorar com] fere a "norma culta", que não aceita tal construção, atrelando a noção abstrata de norma a uma entidade homogênea e estável, desconsiderando que "o uso culto tem abundância de formas alternativas e não se reduz a preceitos estreitos e rígidos" (FARACO, 2008, p. 64).

Ao consultarmos, no entanto, o Dicionário prático de regência verbal, do Prof. Celso Pedro Luft (2010, p. 342), um dos mais importantes e reconhecidos filólogos e linguistas do país, encontramos a seguinte orientação quanto ao verbo namorar: "A regência primitiva é de transitivo direto. Por isso, puristas condenam a regência 'namorar com...' que, no entanto, é normal, de uso perfeitamente legítimo moldado em casar com e noivar com". Ou seja, por pressões semânticas das construções casar com e noivar com a regência do verbo namorar se alterou e parece seguir o curso normal da variação, adequando-se às novas realidades comunicativas requeridas pelo uso da lingua.

Diante disso, qual deve ser a postura do revisor? Ao alterar a regência "incorreta", inconscientemente, ele se filia à noção de língua como um constructo homogêneo e imutável. Se, no entanto, o revisor tem em mente tais questões, e amparado em materiais fruto da criteriosa investigação linguística e filológica, ele possui condições de ampliar a noção de língua, tendo maior clareza do que intervir no seu trabalho.

Ao afirmar que "o revisor pode transformar desde meras palavras aqui e ali, até parágrafos inteiros, editando-os ou enriquecendo-os com a inserção de novos vocábulos", o Manual (2011, p. 17) parece transparecer uma concepção abstrata da palavra, desvinculada de seu conteúdo ideológico e vivencial, contrariando inclusive a afirmação de que é preciso respeitar o estilo, haja vista que o campo semântico das áreas de conhecimento possui usos vocabulares específicos que não podem ser alterados aleatoriamente ao gosto do revisor.

Falar em inserção de novos vocábulos é trazer para a discussão os complexos processos de sinonímia, que, no caso da revisão, quase sempre estão ligados a preocupações quanto à repetição de palavras que supostamente empobrecem o texto. Essa visão deve ser bem compreendida, e o revisor precisa saber quando a repetição de palavras é realmente um caso de pobreza vocabular e quando a repetição é necessária inclusive como recurso de coesão. A afirmação do Manual (2011) sem as devidas considerações pode parecer uma licença indiscriminada na tarefa de intervenção do revisor, pois, "se concedermos um estatuto separado à forma linguística vazia da ideologia, só encontraremos sinais e não mais signos de linguagem" (VOLOCHÍNOV, 2014, p. 99).

Ao revisor, é necessário ter em mente que os pressupostos que defende no trabalho de leitura/revisão implícita ou explicitamente se vinculam a uma forma de encarar esses aspectos e isso modifica o trabalho que se realiza com a língua. É necessária, pois,

[...] a urgência de se considerar a lingua como uma atividade social, em que o importante não é o enunciado, o produto, mas sim a enunciação, o processo verbal. Para Volochínov, a lingua é - tal como para Saussure - um fato social, 
cuja existência se funda nas necessidades da comunicação. Mas, contrariamente à linguística saussuriana e pós-saussuriana, que faz da língua um objeto ideal (um "arco-íris imóvel sobre o fluxo da lingua", como escreve Volochinov), que se consagra à língua como sistema sincrônico homogêneo e rejeita suas manifestações (a fala, parole) como individuais, Volochinov enfatiza precisamente a fala, a parole, a enunciação, e afirma sua natureza social, não individual: a parole está indissoluvelmente ligada às condições de comunicação, que estão sempre ligadas às estruturas sociais (BAGNO, 2012, p. 57, grifo do autor).

O trabalho com o texto, portanto, requer do profissional revisor conhecimentos que ultrapassem os limites do estudo tradicional, abstrato e formal da lingua e da sentença - fonologia, morfologia e sintaxe formal -, áreas importantes que devem ser levadas em consideração sem dúvida, mas que, por si sós, não dão conta dos aspectos contextuais, semânticos e pragmáticos do "fenômeno texto".

O texto, para além de um produto que se encerra em regras abstratamente formuladas para funcionar em uma sociedade ideal (e com sujeitos falantes ideais), constitui-se como uma unidade linguística hierarquicamente superior à frase; o arcabouço teórico utilizado tradicionalmente para estudá-la e descrevê-la não consegue dar conta de explicar as propriedades que fazem um texto ser um texto e não uma união de palavras ou sentenças.

É fundamental encarar o texto como uma unidade de outra natureza, que apresenta propriedades e mecanismos de funcionamento distintos do funcionamento frasal, e tratar a língua como discurso. O trabalho com a revisão pode proporcionar maior conhecimento sobre o funcionamento dos textos e da língua em uso, fornecendo melhor embasamento ao trabalho dos profissionais que atuam com a revisão, se transitarmos por caminhos cujas noções de língua sejam mais alargadas.

\section{CONSIDERAÇões FINAIS}

O estudo abordou as concepções de língua objetivismo abstrato e subjetivismo idealista que fundamentam as principais correntes linguísticas surgidas a partir dos séculos XIX/XX e que impactaram a produção científica no campo da linguagem. Foram apresentados alguns pressupostos que fundamentam essas noções, visando identificar traços de uma ou outra em um manual de revisão de textos, tendo como propósito discutir como a filiação explícita ou implícita a uma concepção específica de língua pode nortear o trabalho com a revisão de textos.

Esperamos que a discussão contribua para o propósito de demonstrar aos revisores a importância de se ter clara a concepção de lingua quando se trabalha com ela, pois a forma de concebê-la altera o modo de encarar os fenômenos linguísticos na unidade hierarquicamente superior à frase, que é o texto.

\section{LANGUAGE CONCEPTIONS AND THEIR IMPLICATIONS FOR THE PRACTICE OF TEXTUAL REVISION}

Abstract: This study briefly presents the language conceptions called abstract objectivism and idealistic subjectivism, which substantiate the main currents of 
linguistics in the twentieth century. It aims to identify their characteristics in the chapter "Conceitos gerais", in the handbook Revisão de textos: teoria e prática. In order to do that, three aspects dealt with in the handbook will be analyzed, namely: 1 . the concept of reviser; 2 . the act of reading for revision; 3. the intervention of the reviser. From these aspects, there will be a discussion on how the explicit or implicit affiliation to a language conception can guide the work of textual revision.

Keywords: Abstract objectivism. Idealistic subjectivism. Text review.

\section{REFERÊNCIAS}

ANTUNES, I. O estudo da língua. In: ANTUNES, I. Lutar com palavras: coesão e coerência. São Paulo: Parábola Editorial, 2005. p. 23-41.

ATHAYDE, P. Revisão de textos: teoria e prática. Belo Horizonte: Keimelion, 2011.

BAGNO, M. A caverna implodida - por uma concepção não platônica de língua. In: BAGNO, M. Gramática pedagógica do português brasileiro. São Paulo: Parábola Editorial, 2012. p. 37-79.

BAKHTIN, M. [VOLOCHÍNOV]. Marxismo e filosofia da linguagem. 16. ed. São Paulo: Hucitec, 2014.

CHOMSKY, N. A. O conhecimento da lingua: sua natureza, origem e uso. Tradução Anabela Gonçalves e Ana Teresa Alves. Lisboa: Caminho, 1994.

CHOMSKY, N. A. Arquitetura da linguagem. Tradução Alexandre Morales e Rafael Ferreira Coelho. Bauru: Edusc, 2008. (Coleção Signum).

FARACO, C. A. Norma culta brasileira: desatando alguns nós. São Paulo: Parábola Editorial, 2008.

FLORES, V. N.; TEIXEIRA, M. Introdução à linguística da enunciação. São Paulo: Contexto, 2013.

LUCCHESI, D. A primazia do sistema e o ostracismo da mudança. In: LUCCHESI, D. Sistema, mudança e linguagem: um percurso na história da linguística moderna. São Paulo: Parábola Editorial, 2004. p. 39-52.

LUFT, C. P. Dicionário prático de regência verbal - nova ortografia. São Paulo: Ática, 2010.

NICOLA, J. de; TERRA, E. 1001 dúvidas de português - versão portátil. São Paulo: Saraiva, 2006.

OLIVEIRA, R. R. F. de. Um olhar dialógico sobre a atividade de revisão de textos escritos: entrelaçando dizeres e saberes. 2007. 172 f. Tese (Doutorado em Letras) - Universidade Federal do Rio Grande do Norte, Natal, 2007.

OLIVEIRA, R. R. F. de. Revisão de textos: da prática à teoria. Natal: EDUFRN, 2016.

ROCHA, H. Um novo paradigma de revisão de textos: discurso, gênero e multimodalidade. 2012. 246 f. Tese (Doutorado em Linguística) - Universidade de Brasília, Brasília, 2012. 
SAUSSURE, F. de. Curso de lingüística geral. Tradução Antônio Chelini, José Paes e Izidoro Blikstein. 20. ed. São Paulo: Cultrix, 1995.

TRAVAGLIA, L. C. Gramática e interação: uma proposta para o ensino de gramática. 10. ed. São Paulo: Cortez, 2005.

WEEDWOOD, B. História concisa da lingüística. Tradução Marcos Bagno. 4. ed. São Paulo: Parábola Editorial, 2002.

Recebido em 24 de novembro de 2018. Aprovado em 23 de abril de 2019. 